\title{
Differences in subtype distribution of Haemophilus influenzae type b from carriers in the general population and patients with meningitis
}

\author{
L. VAN ALPHEN*, P. BOL, M. L. J. KOK and L. GEELEN-VAN DEN BROEK \\ Department of Medical Microbiology, University of Amsterdam and WHO Collaborative Centre for Bacterial Meningitis, \\ Academic Medical Centre, Amsterdam, The Netherlands
}

\begin{abstract}
Summary. Twenty-four Haemophilus influenzae type b strains from 836 children and young adults in an open population were subtyped by outer-membrane-protein (OMP) analysis on sodium dodecyl sulphate-polyacrylamide gels, lipopolysaccharide serotyping and biotyping. The results were compared with those obtained with $\boldsymbol{H}$. influenzae type b strains from 97 patients with meningitis in the same city (Amsterdam). OMP subtype 1 was significantly more common among the CSF isolates than in carrier strains $(82 \%$ vs $50 \% ; \mathrm{p}<0.002)$. The other OMP subtypes found among carriers were rarely isolated from patients. The lipopolysaccharide serotype and biotype distribution did not differ between the two groups. The combination of OMP subtype 1 , lipopolysaccharide 1 , biotype I was much more common in isolates from patients than in those from carriers $(71 \%$ vs $42 \%$; $<0.01)$. The data suggest that various $H$. influenzae type b subtypes are less virulent than those commonly isolated from invasive infections.
\end{abstract}

\section{Introduction}

More than $95 \%$ of systemic Haemophilus influenzae infections are caused by type $b$ strains. In The Netherlands, infants under the age of four years are affected mainly with a peak incidence amongst those aged 8-9 months. ${ }^{1-3}$ Although $\boldsymbol{H}$. influenzae is part of the normal nasopharyngeal flora, type $b$ strains are found in only a minority of healthy people (especially young children); colonisation rates vary considerably in open populations. ${ }^{4}$

Person to person spread supposedly occurs by transmission of respiratory tract secretions. Increased $H$. influenzae type b carriage among young household and day-care contacts of patients with $\boldsymbol{H}$. influenzae type $b$ disease correlates with a higher incidence of disease among such contacts. ${ }^{5}$ In the open population carriage rates were reported to be independent of the risk of invasive infection with $H$. influenzae type $\mathrm{b}^{6}{ }^{6}$ This discrepancy may be explained by a difference among $H$. influenzae type b strains in their potential to colonise the nasopharynx and their ability to cause systemic disease. ${ }^{7}$

$H$. influenzae type $\mathrm{b}$ is subdivided by analysis of the major outer membrane proteins (OMPs) by sodium dodecyl sulphate-polyacrylamide gel electrophoresis

Received 4 April 1990; revised version accepted 10 Aug. 1990. * Correspondence should be sent to Dr L. van Alphen, Department of Medical Microbiology, Room L162, University of Amsterdam, Meibergdreef 15, NL-1105 AZ Amsterdam, The Netherlands.
(SDS-PAGE) (OMP subtyping), lipopolysaccharide (LPS) serotyping and biotyping (BT). OMP subtyping was shown to be highly discriminatory. ${ }^{8,9}$ Hampton et al. ${ }^{10}$ found that the subtypes isolated from patients with $H$. influenzae type $\mathrm{b}$ disease occurred also in carriers. In contrast, strains of OMP subtype 13L were found significantly more often among carriers in an open population than in patients. The numbers in this study were too low to conclude which subtypes of $H$. influenzae type b are typical carriage strains. It was a particular difficulty of this study that a large number of subtypes was found in the USA among isolates from patients with systemic disease. ${ }^{9}$ In The Netherlands, $H$. influenzae type b OMP subtype 1 strains are almost exclusively responsible for cases of haemophilus meningitis, 1,8,11 and typical carriage subtypes can be identified easily. Therefore, we have compared the subtype distribution of $\boldsymbol{H}$. influenzae type b strains isolated from patients and from carriers in an open population in Amsterdam.

\section{Materials and methods}

\section{Study population and collection of samples}

Carriage strains were obtained with informed consent. Throat swabs were taken from 492 children aged 4-12 years who attended four City Health Board Centres in Amsterdam for routine vaccinations. Additionally, samples were taken from 196 infants 
aged $0-1$ years attending two Infant Health Board Centres and from 148 undergraduate students of medicine and biology aged between 20 and 30 years. All samples were collected between December 1986 and April 1987. Isolates of $H$. influenzae type b from invasive disease were obtained from 97 patients with meningitis who were admitted to hospitals in Amsterdam from 1975 to 1987 . A randomly selected series of $80 \mathrm{H}$. influenzae type b strains isolated from patients with meningitis in The Netherlands between 1975 and 1980 and another 96 isolates collected in 1987 were used as reference strains. These strains were collected as part of a nationwide surveillance based on collaboration with the bacteriologists of the Regional Health Laboratories. The submission rate for these meningitis isolates increased from $60 \%$ to more than $80 \%$ during the first years of the investigation period. ${ }^{12}$

\section{Isolation and typing of $H$. influenzae}

Throat swabs were cultured on brain-heart infusion agar supplemented with Levinthal base, NAD $10 \mathrm{mg} /$ $\mathrm{L}$, bacitracin $5 \mathrm{U} / \mathrm{ml}$ and with antiserum to $H$. influenzae type $\mathrm{b}(0.45 \mathrm{ml} / 10-\mathrm{ml}$ plate $)$ according to the method described by Michaels et al. ${ }^{13}$ Antiserum was raised in sheep by the method described previously for raising antisera in rabbits. ${ }^{8}$ The plates were incubated for $36-44 \mathrm{~h}$ at $37^{\circ} \mathrm{C}$ in a humid atmosphere of air with $\mathrm{CO}_{2} 5 \%$. Halo-forming bacteria were selected from all plates. All strains isolated from throat swabs and from CSF were examined for dependence on haemin and NAD for growth, for the inability to convert $\delta$-aminolevulanic acid, and for the presence of a capsule detectable by coagglutination with type specific antisera as described previously. ${ }^{8}$

OMP subtyping was performed by SDS-PAGE of the major OMPs on a linear SDS-polyacrylamide gel after boiling the bacterial cell envelope preparations for $5 \mathrm{~min}$ or warming for $30 \mathrm{~min}$ at $37^{\circ} \mathrm{C}$ in SDS $1 \%$ as described previously. ${ }^{8}$ A panel of reference strains obtained from Dr D. M. Granoff (St. Louis, USA) and from our own collection were used for comparison. ${ }^{9}$ LPS serotyping was performed with monoclonal antibodies (MAbs) specific for LPS-1 and LPS-10 in a whole cell ELISA as described by Abdillahi and Poolman. ${ }^{14}$ Details of the production and characterisation of these MAbs have been published elsewhere. ${ }^{15}$ Strains which gave negative results in this test were analysed further by Ouchterlony immunodiffusion with polyclonal LPS-specific antisera as described previously ${ }^{8}$ and elsewhere. ${ }^{16}$ Biotyping was performed according to the method developed by Kilian. ${ }^{17}$

\section{Statistical analysis}

Analysis of differences was performed with the $\chi^{2}$ test (two-sided, 1df, Yates's correction when necessary), the Odds Ratio (OR), Fisher's exact test (twosided) and with $95 \%$ binomial confidence intervals (CI95).

\section{Results}

\section{Carriage of $H$. influenzae type b in Amsterdam}

From a total of 836 throat swabs processed, 26 carriers of $\boldsymbol{H}$. influenzae type b were found among 688 children under 12 years $(3.8 \%)$ but none among the 148 adults tested (table I). The lowest carriage rate of $H$. influenzae type $\mathrm{b}$ in the group of children aged under 12 years was in infants under 1 year, the highest in children of 11 and 12 years. The age-distribution of carriage differed strongly from that of meningitis, cases of which are almost entirely restricted to children under 5 years. ${ }^{1-3}$

\section{Biotypes, OMP subtypes and LPS serotypes of $H$. influenzae type b among patients with meningitis and carriers}

Of the 26 carriage strains, 24 were available for further analysis and the results are summarised in table II. Most (19) of the carrier strains were BT I, four strains were BT II and one strain was BT V. The percentage of BT I strains $(79 \%)$ was not significantly different from the proportion among meningitis strains in Amsterdam (85\%).

With OMP subtyping, 12 of the 24 carriage strains were subtype 1 ; the others belonged to various subtypes which have also been found among strains from patients with meningitis, albeit rarely. This percentage of subtype 1 strains among carriers $(50 \%)$ was much lower than that among patients with meningitis in Amsterdam, since $80(82 \%)$ of 97 patient strains were subtype 1. This difference is highly significant $\left(\chi^{2}=9.42, \mathrm{p}=0.002 ; \mathrm{OR}=4 \cdot 71,1.64<\mathrm{OR}<13.67\right)$. As the patient strains were collected between 1975 and 1987 and the carrier strains were collected only in 1987 , we considered the possibility that the distribution of subtypes had changed between 1975 and 1987. Therefore, we compared the relative contribution of OMP 1 strains among patient strains in The Netherlands in 1987 with the data on strains isolated between 1975 and 1980 published previously. ${ }^{8}$ The percentage of OMP 1 strains had hardly changed during this period $(84 \%$ in $1975-1980$ and $89 \%$ in 1987$)$. The effect of the difference in age distribution between carriers

Table I. $H$. influenzae type b carriers and meningitis cases in The Netherlands

\begin{tabular}{c|rccc}
\hline $\begin{array}{c}\text { Age group } \\
\text { (years) }\end{array}$ & $\begin{array}{c}\text { Number } \\
\text { of carriers } \\
(\%)\end{array}$ & $\begin{array}{c}\text { Number } \\
\text { examined }\end{array}$ & CI95 & $\begin{array}{c}\text { Cases of men- } \\
\text { ingitis per } \\
100000^{*}\end{array}$ \\
\hline $0-1$ & $2(1 \cdot 0)$ & 196 & $0 \cdot 1-3 \cdot 6 \%$ & $38 \cdot 4$ \\
$2-5$ & $8(4 \cdot 7)$ & 169 & $2 \cdot 0-9 \cdot 1 \%$ & $10 \cdot 0$ \\
$6-12$ & $16(5 \cdot 0)$ & 323 & $2 \cdot 9-6 \cdot 9 \%$ & $0 \cdot 32$ \\
Total (0-12) & $26(3 \cdot 9)$ & 668 & $2 \cdot 5-5 \cdot 5 \%$ & $\ldots$ \\
Adults (20-30) & $0(0 \cdot 0)$ & 148 & $0 \cdot 0-2 \cdot 4 \%$ & $\ldots$ \\
\hline
\end{tabular}

* Incidence data for $1982 .{ }^{1,12}$ 
Table II. Subtyping of carriage and meningitis strains of $H$. influenzae type b from Amsterdam and The Netherlands

\begin{tabular}{|c|c|c|c|c|c|c|c|c|c|c|c|c|c|c|c|c|c|c|c|c|c|c|c|}
\hline \multirow{3}{*}{ Source of strains } & \multirow{3}{*}{$\begin{array}{c}\text { Year } \\
\text { of } \\
\text { isolation }\end{array}$} & \multirow{3}{*}{$\begin{array}{c}\text { Number } \\
\text { tested }\end{array}$} & \multicolumn{21}{|c|}{ Number of strains of } \\
\hline & & & \multicolumn{7}{|c|}{ OMP subtype } & \multicolumn{4}{|c|}{ BT } & \multicolumn{10}{|c|}{ LPS serotype } \\
\hline & & & $1^{*}$ & 1a & $1 b$ & lc & 2 & 3 & others & I & & IV & V & 12 & 3 & 4 & 5 & 6 & 7 & 8 & 9 & 10 & NT \\
\hline Carriers (Amsterdam) & 1987 & 24 & 12 & 3 & 3 & 1 & 2 & 1 & 2 & 19 & 4 & 0 & 1 & 170 & 0 & 0 & 0 & 0 & 0 & 0 & 3 & 1 & 3 \\
\hline Patients (Amsterdam) & $1975-1987$ & 97 & 80 & 2 & 0 & 4 & 1 & 5 & 5 & 82 & 12 & 2 & 1 & 810 & 1 & 0 & 0 & 4 & 3 & 0 & 0 & 5 & 3 \\
\hline Patients (Netherlands) & $1975-1980$ & 80 & 67 & 6 & 2 & 0 & 4 & 1 & 0 & 77 & 3 & 0 & 0 & 742 & 1 & 1 & 0 & 0 & 0 & 0 & 0 & 0 & 2 \\
\hline Patients (Netherlands) & 1987 & 96 & 85 & 6 & 1 & 1 & $\mathbf{0}$ & $\mathbf{0}$ & 3 & 93 & 3 & 0 & 0 & 920 & 0 & 0 & 0 & 0 & 0 & 0 & 1 & 0 & 3 \\
\hline
\end{tabular}

* Subtype 1 is identical with subtype $3 \mathrm{~L}$ described by Barenkamp et al. ; $^{5}$ subtypes $1 \mathrm{~b}$ with $16 \mathrm{~L}, 2$ with $2 \mathrm{~L}$ and 3 with $6 \mathrm{U}$.

and patients on subtype distribution between carrier and patient strains was analysed by comparing the subtype distribution of strains from carriers $0-5$ years old with those from older children. Subtype 1 was found in six of 10 carriers in the younger group and in six of 14 older children, indicating that the common subtype was not more common in the at risk age group (0-5 years).

The LPS serotype distribution of carrier and patient strains was slightly different. LPS-1 was less common among carriers $(71 \%)$ than among patients $(82 \%)$ in Amsterdam, but this difference was not significant $(p=0 \cdot 16$, Fisher's exact test). Ten $(42 \%)$ of 24 carrier strains and $69(71 \%)$ of 97 patient strains were OMP subtype 1, LPS-1, biotype I indicating that the various subtyping characters were associated. This difference is significant $\left(\chi^{2}=5.91, \mathrm{p}<0.01 ; \mathrm{OR}=3.45\right)$.

\section{Discussion}

Subtype OMP 1 of $\boldsymbol{H}$. influenzae type b, commonly isolated from patients with meningitis was found significantly less frequently in carriers when strains isolated in the same city (Amsterdam) were examined. Although the periods of isolation were not the same, this could not explain the difference in subtype distribution because the relative contribution of the common subtype did not vary significantly during the study period in The Netherlands (table I). It is very unlikely that this difference was due to differences in age distribution between carriers and patients, because the relative contribution of subtype 1 strains in carriers below and above 5 years of age was similar $(43 \%$ vs $60 \%$; the percentage for the whole group was $50 \%$ ). Unfortunately, it was not possible to draw firm conclusions in this respect because the numbers of strains in each group were too low. Interestingly, we did not find subtype 13L strains among the carrier isolates, as found by Hampton et al. ${ }^{10}$ which suggests that carriage strains and disease isolates have a similar restricted geographical distribution. ${ }^{11}$

Subtypes other than subtype 1 found among carriers were also, rarely, isolated from meningitis patients in this study as described previously. $5,8,11$ The 'rare' subtypes are found mostly in patients over 6 years old with predisposing factors. ${ }^{3,7}$ This indicates that strains of these uncommon subtypes are less virulent and that only a few subtypes have the pathogenic properties required for invasive disease. It is not yet possible to determine whether OMPs are important for virulence or whether they are just markers for different clones with many more specific characteristics. ${ }^{18}$ The combined occurrence of OMP subtype 1 with LPS-1 and biotype I among $\boldsymbol{H}$. influenzae type b isolates from patients $(71 \%)$ and carriers $(42 \%)$ supports the clonal hypothesis.

A greater association of LPS-1 with meningitis than with carriage could not be demonstrated, nor was another LPS serotype found exclusively among patients or carriers. A special LPS structure may not be required for invasive disease. In this respect it is interesting to note that Kimura and Hansen have found a reduction in the virulence of $H$. influenzae type b strains following the loss of some LPS epitopes. ${ }^{19}$ This result not only indicates that LPS is important for virulence, but also that the capsular polysaccharide alone is insufficient.

The differences in subtype and age distribution of $H$. influenzae type $\mathrm{b}$ in carriers and cases indicate that risk of causing disease cannot be deduced directly from data on the carriage of $\boldsymbol{H}$. influenzae type $\mathrm{b}$ without taking account of subtype distribution. This conclusion is in agreement with data from Hall and colleagues $^{20}$ who showed that invasive disease in Alaskan Eskimos was caused by subtypes other than those found among carriers in the same village in the same period. Furthermore, Bijlmer et al. did not observe any cases of meningitis in villages in The Gambia where carriage rates rose to $40 \%{ }^{21}$ However, the same subtypes of $\boldsymbol{H}$. influenzae type b were found among cases and carriers in this study and others. ${ }^{6,10}$ Therefore, carriage would appear to contribute to the spread of $H$. influenzae disease, but in an unpredictable way. The effect of carriage on the acquisition of protective immunity during childhood may be responsible for this unpredictable pattern.

We thank L. Wijgergangs, B. Kalwij and H. Pauw, for their help in collecting carriage strains in the general population, and $L$. Dekker for subtyping some of the strains. Drs H. A. Bijlmer and R. Segaar are acknowledged for critically reading the manuscript and for help with statistical analysis. 


\section{References}

1. RBM (Netherlands' Reference Laboratory for Bacterial Meningitis). Bacterial meningitis in The Netherlands (annual reports 1980-1988). Amsterdam, University of Amsterdam. 1981-1987.

2. Bol P. Epidemiology of bacterial meningitis in The Netherlands. Vol. II. PhD Thesis. Amsterdam, University of Amsterdam. 1987.

3. van Alphen L, van Dam A, Bol P, Spanjaard L, Zanen HC. Types and subtypes of 73 strains of Haemophilus influenzae isolated from patients more than 6 years of age with meningitis in The Netherlands. J Infect 1987; 15:95-101.

4. Turk DC, May JR. Haemophilus influenzae: its clinical importance. London. The English University Press. 1967: 1323.

5. Barenkamp SJ, Granoff DM, Munson RS. Outer-membrane protein subtypes of Haemophilus influenzae type b and spread of disease in day-care centers. J Infect Dis 1981; 144: $210-217$.

6. Granoff DM, Daum RS. Spread of Haemophilus influenzae type b: recent epidemiologic and therapeutic considerations. $J$ Pediatr 1980; 97: 854-860.

7. Bol P, Spanjaard L, van Alphen L, Zanen HC. Epidemiology of Haemophilus influenzae meningitis in patients more than 6 years of age. $J$ Infect $1987 ; 15: 81-94$.

8. van Alphen L, Riemens T, Poolman J, Hopman C, Zanen HC. Homogeneity of cell envelope protein subtypes, lipopolysaccharide serotypes, and biotypes among Haemophilus influenzae type $\mathrm{b}$ from patients with meningitis in The Netherlands. J Infect Dis $1983 ; 148: 75-81$.

9. Barenkamp SJ, Munson RS, Granoff DM. Comparison of outer-membrane protein subtypes and biotypes of isolates of Haemophilus influenzae type b. J Infect Dis $1981 ; 144$ : 480.

10. Hampton CM, Barenkamp SJ, Granoff DM. Comparison of outer membrane protein subtypes of Haemophilusinfluenzae type $b$ isolates from healthy children in the general population and from diseased patients. J Clin Microbiol 1983; 18: 596-600.

11. van Alphen L, Geelen L, Jónsdóttir K, Takala AK, Kãyhty H,
Zanen HC. Distinct geographic distribution of subtypes of Haemophilus influenzae type b in Western Europe. J Infect Dis 1987 ; 156 : 216-218.

12. Spanjaard L, Bol P, Ekker W, Zanen HC. The incidence of bacterial meningitis in The Netherlands: a comparison of three registration systems, 1977-1982. J Infect 1985; 11 : 259-268.

13. Michaels RH, Stonebraker FE, Robbins JB. Use of antiserum agar for detection of Haemophilus influenzae type $b$ in the pharynx. Paediatr Res 1975; 9: 513-516.

14. Abdillahi H, Poolman JT. Whole-cell ELISA for typing Neisseria meningitidis with monoclonal antibodies. FEMS Microbiol Lett. 1987; 48: 367-371.

15. van Alphen L, van den Berghe N, Geelen-van den Broek L. Interaction of Haemophilus influenzae with human erythrocytes and oropharyngeal epithelial cells is mediated by a common fimbrial epitope. Infect Immun 1988; 56: 18001806.

16. van Alphen L, Klein M, Geelen-van den Broek L, Riemens T Eijk P Kamerling JP. Biochemical characterization and worldwide distribution of serologically distinct lipopolysaccharides of Haemophilus influenzae type b. $J$ Infect Dis $1990 ; 162$ : 659-663.

17. Kilian M. A taxonomic study of the genus Haemophilus, with the proposal of a new species. J Gen Microbiol 1976; 93: 9 62.

18. Musser JM, Barenkamp SJ, Granoff DM, Selander RK. Genetic relationships of serologically nontypable and serotype b strains of Haemophilus influenzae. Infect Immun 1986; 52: 183-191.

19. Kimura A, Hansen EJ. Antigenic and phenotypic variations of Haemophilus infuenzae type b lipopolysaccharide and their relationship to virulence. Infect Immun 1986; 51: 69-79.

20. Hall DB, Lum MKW, Knutson LR, Heyward WL, Ward JI Pharyngeal carriage and acquisition of anticapsular antibody to Haemophilus influenzae type $\mathrm{b}$ in a high-risk population in southwestern Alaska. Am J Epidemiol 1987; 126: 1190-1197.

21. Bijlmer HA, Lloyd Evans N, Campbell $\mathrm{H}$ et al. Carriage of Haemophilus influenzae in healthy Gambian children. Trans R Soc Trop Med Hyg 1989; 83: 831-835. 